PREPARED FOR THE U.S. DEPARTMENT OF ENERGY, UNDER CONTRACT DE-AC02-76CH03073

PPPL-3567

PPPL-3567

UC-70

Expansion Rate Measurements at Moderate Pressure of Nonneutral Electron Plasmas in the Electron Diffusion Gauge (EDG) Experiment

Kyle A. Morrison, Ronald C. Davidson, Stephen F. Paul, Emily A. Belli, and Edward H. Chao

May 2001
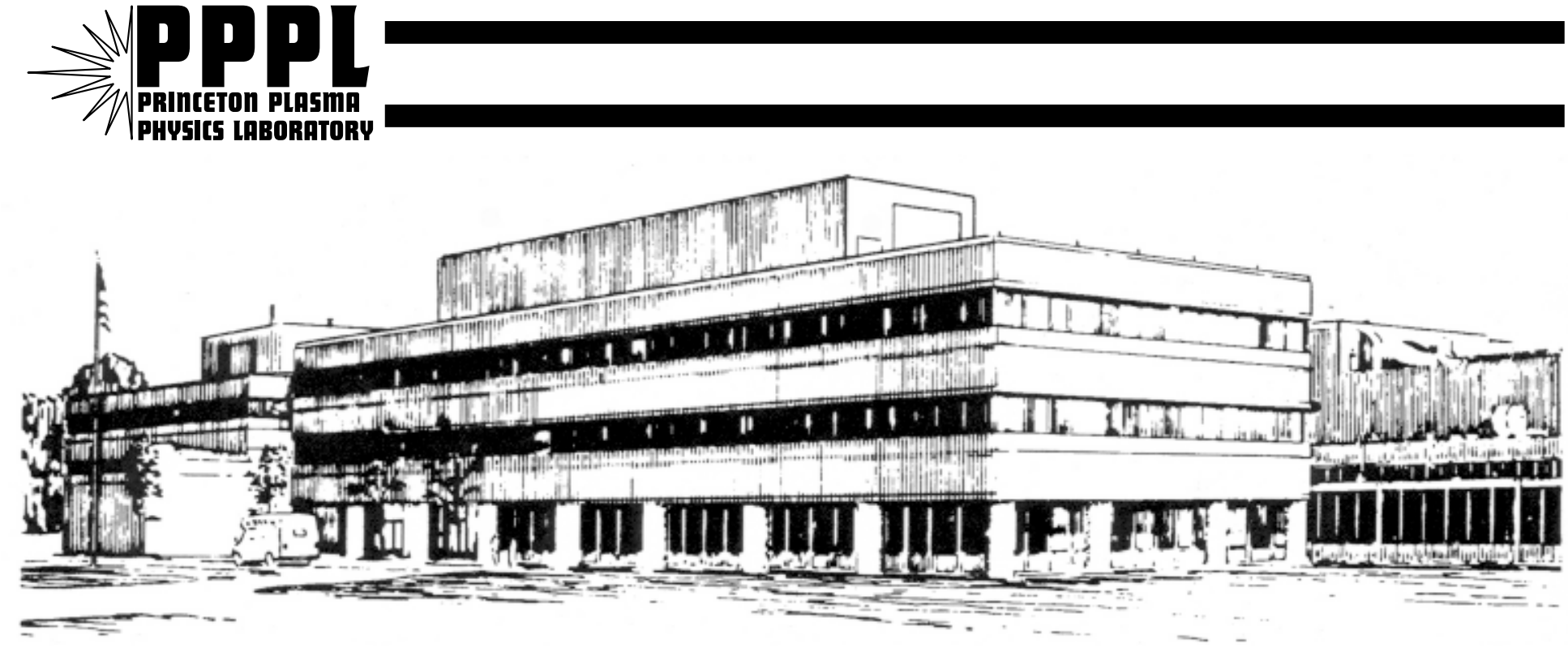

PRINCETON PLASMA PHYSICS LABORATORY PRINCETON UNIVERSITY, PRINCETON, NEW JERSEY 


\section{PPPL Reports Disclaimer}

This report was prepared as an account of work sponsored by an agency of the United States Government. Neither the United States Government nor any agency thereof, nor any of their employees, makes any warranty, express or implied, or assumes any legal liability or responsibility for the accuracy, completeness, or usefulness of any information, apparatus, product, or process disclosed, or represents that its use would not infringe privately owned rights. Reference herein to any specific commercial product, process, or service by trade name, trademark, manufacturer, or otherwise, does not necessarily constitute or imply its endorsement, recommendation, or favoring by the United States Government or any agency thereof. The views and opinions of authors expressed herein do not necessarily state or reflect those of the United States Government or any agency thereof.

\section{Availability}

This report is posted on the U.S. Department of Energy's Princeton Plasma Physics Laboratory Publications and Reports web site in Calendar Year 2001. The home page for PPPL Reports and Publications is: http://www.pppl.gov/pub_report/

DOE and DOE Contractors can obtain copies of this report from:

U.S. Department of Energy

Office of Scientific and Technical Information

DOE Technical Information Services (DTIS)

P.O. Box 62

Oak Ridge, TN 37831

Telephone: (865) 576-8401

Fax: (865) 576-5728

Email: reports@adonis.osti.gov

This report is available to the general public from:

National Technical Information Service

U.S. Department of Commerce

5285 Port Royal Road

Springfield, VA 22161

Telephone: 1-800-553-6847 or

(703) 605-6000

Fax: (703) 321-8547

Internet: http://www.ntis.gov/ordering.htm 


\title{
Expansion Rate Measurements at Moderate Pressure of Nonneutral Electron Plasmas in the Electron Diffusion Gauge (EDG) Experiment.
}

\author{
Kyle A. Morrison, Ronald C. Davidson, Stephen F. Paul, \\ Emily A. Belli and Edward H. Chao* \\ Plasma Physics Laboratory \\ Princeton University \\ Princeton, NJ 08543
}

\begin{abstract}
Measurements of the expansion rate of pure-electron plasmas have been performed on the Electron Diffusion Gauge (EDG) device at background helium gas pressures in the $5 \times 10^{-8}$ Torr to $1 \times 10^{-5}$ Torr range, where plasma expansion due to electron-neutral collisions dominates over plasma expansion due to trap asymmetries. It is found that the expansion rate, defined as the time rate of change of the particles' mean-square radius, scales approximately linearly with pressure and inversely as the square of the magnetic field strength in this regime, in agreement with classical predictions.
\end{abstract}

Typeset using REVTEX

${ }^{*}$ Currently at GE Medical Systems, Milwaukee, WI 53201. 
Pure electron plasmas are trapped in the Electron Diffusion Gauge (EDG) device, ${ }^{1-4}$ a cylindrically symmetric Malmberg-Penning trap ${ }^{5}$ with wall radius $R_{w}=2.54 \mathrm{~cm}$. Similar trap configurations are often used for the experimental study of nonneutral plasmas $^{6,7}$. Nonneutral plasmas are studied in research to develop atomic clocks ${ }^{8-10}$, investigations of turbulence, nonlinear vortex dynamics, and instabilities in nearly-inviscid two-dimensional fluids ${ }^{11-18}$, research on particle transport across magnetic field lines in quiescent plasmas ${ }^{19-23}$, investigations of the properties of nonneutral plasmas in thermal equilibrium ${ }^{24,25}$, and in experiments to study the formation and confinement of positron plasmas $^{26-28}$. Many of these experiments ${ }^{8,13,19,24-26}$ are performed at vacuum pressures in the range where background neutrals are observed to affect the plasma dynamical behavior and confinement properties.

Previously reported experimental results ${ }^{1}$ from the EDG device, carried out with a helium background pressure in the $4 \times 10^{-10}$ to $2 \times 10^{-7}$ Torr range, indicated that the expansion rate of the plasmas is about a factor of four faster than that predicted theoretically. The theoretically predicted expansion rate ${ }^{29}$ is derived using a fluid treatment of the plasma, and assumes that the (elastic) electron-neutral collision frequency is not a function of time beyond its dependence on the plasma temperature. In this communication, further measurements that have been performed at higher helium background pressures $\left(\mathrm{P}_{\mathrm{He}}=1 \times 10^{-7}\right.$ Torr to $2 \times 10^{-5}$ Torr) are reported that support the theoretical prediction. ${ }^{29}$ In addition to the expansion rate scaling with background gas pressure, an analysis of the scaling with magnetic field at higher pressures is also presented.

A Malmberg-Penning trap comprises a uniform magnetic field parallel to the common axis of several identical cylindrical electrodes, the outer two of which are electrically biased. ${ }^{1-5}$ Particles of one sign of charge are confined in the trap radially by the magnetic field, and axially by the applied electric field produced by the biased end electrodes. To measure the number of electrons in the plasma, one of the end electrodes is rapidly grounded, ${ }^{1-5}$ allowing the particles to escape through that end of the trap. In the EDG device, these particles strike a biased plate (the "total" density diagnostic) which contributes to the mea- 
surement of the total plasma charge. The particles along an axial chord aligned with a small, collimating hole in the biased plate pass through to a Faraday cup, which measures the amount of charge along that chord (the "local" density diagnostic). The total amount of charge in the plasma is determined by summing the amounts of charge measured by the two diagnostics. By forming several (well-reproduced) plasmas in succession, a series of line-integrated profiles is obtained, which is used to follow the expansion of the plasma. To determine the plasmas' behavior at different gas pressures, helium gas is fed into the chamber at different, controlled rates to produce the desired background neutral pressure. ${ }^{1-4}$

The expansion rate of the plasma in the EDG device is determined as previously described. $^{1-4}$ The mean-square radius of the plasma is computed numerically according to the expression

$$
\left\langle r^{2}\right\rangle=\frac{\int_{0}^{R_{w}} d r 2 \pi r r^{2} Q(r)}{\int_{0}^{R_{w}} d r 2 \pi r Q(r)}
$$

where

$$
Q(r)=-\frac{e}{\mathrm{~A}_{\mathrm{h}}} \int d z \int_{A_{h}} d r^{\prime} d \theta n\left(r^{\prime}, \theta, z\right)
$$

Here, $A_{h}$ is the area of the collimating hole, and $n\left(r^{\prime}, \theta, z\right)$ is the number density of the plasma electrons. The quantity $Q(r)$ corresponds to the axially-integrated profile that is measured with the local density diagnostic, and is an average over the area of the local density diagnostic's collimating hole (collimating hole radius $=1 / 16 "$ ). The plasma expansion rate may be estimated by fitting a plot of mean-square plasma radius versus time with a curve, and taking the slope of that curve to be the instantaneous expansion rate. In contrast, earlier experiments $^{30,31}$ obtained qualitatively similar scaling results to those presented here with comparable Malmberg-Penning traps by measuring the decay of the plasmas' central density, i.e., both the time it takes for the central density to reach one-half of its initial value, $\tau_{m}$, and the time rate of change of the inverse central density, $(d / d t)[1 / n(r=0, t)]$. For the EDG experiment, however, we have determined the expansion rate from the measured density profiles using a linear fit to the early part of the mean-square radius evolution data. 
When determining the expansion rate in this manner, we use mean-square radius values from profiles taken before a chosen percentage (usually $2 \%$ or $5 \%$ ) of the total charge has been lost from the trap. This is because the total charge confined in the trap decreases more rapidly during the plasma evolution at pressures above $1 \times 10^{-7}$ Torr than it does for the lower-pressure data, ${ }^{1-4}$ where the total charge is nearly constant until the plasma contacts the wall (through radial expansion). Specifically, within the range of the higherpressure data, the charge confined is lost continuously, and more and more rapidly, at higher and higher pressures. The increased charge loss was not anticipated, as the plasma profiles appear to be well-removed from the wall at least during the early stages of expansion. The only other apparent opportunity for electrons to escape is through the end potentials held at $-147 \mathrm{~V}$, which is unlikely as the plasma potential on axis is routinely about $-12 \mathrm{~V}$, and the plasma temperatures have been inferred from fits to the density profile ${ }^{1-4}$ to be about $2 \mathrm{eV}$.

Figure 1 shows the composite result of the experimental measurements at $B=610 \mathrm{G}$ magnetic field. This value of magnetic field is used because it provides the largest range of pressures with measurable expansion rate data in the EDG device, and the data can be compared with data from previous studies. ${ }^{1-4}$ The data ranging over background pressures of $3 \times 10^{-10}$ Torr to $2 \times 10^{-7}$ Torr, represented by squares, are the data from the previous studies. The data ranging over background pressures of $1 \times 10^{-7}$ Torr to $2 \times 10^{-5}$ Torr, represented by diamonds, correspond to the new measurements. Each set of mean-square radii data at a particular pressure is represented twice on this plot. Open squares denote the expansion rate determined using only the first half of the mean-square radius evolution data during a four-second time evolution. Closed squares denote the expansion rate determined by using the entire mean-square radius time evolution. Open diamonds denote expansion rates computed using only mean-square radii data taken before $2 \%$ of the total plasma charge has been lost, and closed diamonds denote expansion rates computed with the data taken before $5 \%$ of the plasma has been lost. The data from the previous studies is represented both by points using the first half of the data and by points using all of the data in an attempt to 
account for the loss in charge at higher pressures. For that data, the total plasma charge was nearly constant until halfway through the evolution in all cases.

The solid curve in the plot in Fig. 1 is the expansion rate predicted theoretically, ${ }^{29}$ with an added offset to account for the effects of trap asymmetries ${ }^{30,32,33}$ at low pressures. The expansion rate in the linear region has previously been calculated ${ }^{29}$ to be

$$
\frac{d}{d t}\left\langle r^{2}\right\rangle=\frac{2 N_{L} e^{2} \nu_{e n}(T)}{m_{e} \omega_{c e}^{2}}\left(1+\frac{2 T}{N_{L} e^{2}}\right),
$$

where $\omega_{c e}=e B / m_{e} c$ is the electron cyclotron frequency, $\nu_{e n}(T)=n_{n} \sigma_{e n} v_{T h}$ is the electronneutral collision frequency, $T$ is the plasma temperature (in ergs), and $N_{L}$ is the line density of the plasma column. The theoretical curve plotted in Fig. 1 assumes $T=2 \mathrm{eV}$ and $N_{L}=3.41 \times 10^{7}$ electrons $/ \mathrm{cm}$, and the offset used is $0.1 \mathrm{~cm}^{2} / \mathrm{sec}$. At pressures exceeding $10^{-7}$ Torr, the data in Fig. 1 is consistent with the linearly-varying theoretical prediction in Eq. (3). The fit to the data obtained for the previous study ${ }^{1}$ resulted in a calculated expansion rate that is factor of four greater than the unadjusted theoretical curve because the data used did not extend to a high enough pressure to produce purely electron-neutral collision-dominated expansion. In that $\operatorname{study}^{1}$, asymmetry-induced expansion was not negligible over any part of the data range. Note that the theoretical curve plotted in Fig. 1 is not a fit, but an absolute prediction of the fluid theory. ${ }^{29}$

In using Eq. (3), however, there is a caveat: at pressures above $\mathrm{P}=10^{-7}$ Torr, the electron-neutral collision frequency in the EDG device is greater than the electron-electron collision frequency ${ }^{34}$, and the assumption of uniform temperature across the cross section of the plasma is not necessarily valid. This assumption is used to derive the equation for the expansion rate in Eq. (3), which nonetheless agrees with the measured data. This is interpreted to mean that any effects of a non-uniform plasma temperature on the expansion rate are negligibly small for the EDG device in this parameter range.

Figure 2 shows the results of higher-pressure expansion measurements taken at $\mathrm{B}=300 \mathrm{G}$ magnetic field. This set of data was taken to establish that the linear dependence of the expansion rate scaling with pressure observed at $\mathrm{B}=610 \mathrm{G}$ was not an artifact of 
that value of the magnetic field. The squares denote expansion rates computed using the measurements taken before $2 \%$ of the plasma has been lost, and the diamonds denote expansion rates computed before $5 \%$ of the plasma has been lost. The amount of data used for the expansion rates denoted by triangles, however, is obtained through a stricter qualitative standard; only profiles that have low relative error in the computation of $\left\langle r^{2}\right\rangle$ were used. This approximate criterion often results in fewer mean-square radius measurements being used in the computation of the expansion rates than for the $2 \%$ case, but in all cases fewer measurements than the number used for the $5 \%$ case.

The $300 \mathrm{G}$ data in Fig. 2 also agree with a linear dependence of the expansion rate on background gas pressure. Of the theoretical curves shown, the curve that best describes the linear portion of the data in Fig. 2 is the one that assumes a temperature of $T=1.5 \mathrm{eV}$. Plasma temperatures inferred for profiles measured at different times can have different values, however, making it difficult to describe the behavior of the expansion rate with a single theoretical curve. In the EDG device, the temperature at a given time is routinely inferred by fitting density profile data with the predicted quasi-equilibrium density profile ${ }^{29}$. It is important to note that the same fluid theory ${ }^{29}$ used to predict the the expansion rate in Eq. (3) is used to predict the quasi-equilibrium density profile, so the inferred temperatures are imperfect indicators of the actual temperature at pressures above $\mathrm{P}=10^{-7}$ Torr. For the expansion rate data in Fig. 2, we note that the computed expansion rates lie between the curves determined with $T=1 \mathrm{eV}$ and $T=2 \mathrm{eV}$.

Expansion rate data has also been taken at $\mathrm{P}=10^{-6}$ Torr at several different values of magnetic field, and the results are presented in Fig. 3. These results indicate that the expansion rate scales as $B^{-2.190} \pm 0.015$ in the EDG device when electron-neutral collisions dominate the expansion (at higher pressures). The previous (lower-pressure) measurements in the EDG device, in the regime where asymmetry-induced expansion dominates, produced a scaling of $B^{-1.5 \pm 0.1}$, which is also at variance with the $(L / B)^{2}$ scaling for that regime reported previously by Driscoll, et. al. ${ }^{35,36}$ The measured scaling at higher pressure in the EDG device is in reasonable agreement with the theoretical scaling $\left(B^{-2}\right)$ in Eq. (3). 
Recent experiments measuring plasma expansion caused by imposed $l=1$ trap asymmetries $^{32}$ in the pressure range where asymmetry-induced expansion is dominant indicate that the expansion rate scaling with magnetic field is proportional to $B^{-2}$. Specifically, it is reported ${ }^{32}$ that the normalized plasma expansion rate $\delta \nu \equiv\left(1 /\left\langle r^{2}\right\rangle\right) d\left\langle r^{2}\right\rangle / d t$ is proportional to $1 / \mathrm{R}^{2} \propto n^{2} L^{2} / T B^{2}$ in the low rigidity regime $(1<\mathrm{R}<10)$, where the rigidity $\mathrm{R}$ of a nonneutral plasma confined in a Malmberg-Penning trap is defined as the ratio of a thermal electron's axial bounce frequency to the average $E \times B$ rotation frequency of the plasma. Furthermore, it has been observed that the $\mathrm{R}^{-2}$ expansion rate scaling is also exhibited for imposed $l=2, l=4$, and one-sector trap asymmetries as well. ${ }^{37}$

The EDG plasma, with characteristic parameters $n \sim 1 \times 10^{7} \mathrm{~cm}^{-3}, L \sim 15 \mathrm{~cm}$, $T \sim 1-4 \mathrm{eV}$, and $B \sim 100-800 \mathrm{G}$, is determined to have a rigidity of $\mathrm{R} \sim 1-15$. The data used for the higher-pressure, neutral-collision-dominated scaling presented are estimated to have rigidities of $\mathrm{R} \sim 1-13$. The $B^{-1.5}$ expansion rate scaling measured in the lower-pressure, asymmetry-dominated regime ${ }^{1}$ on EDG was also measured at rigidities of $\mathrm{R}<10$, however, and does not agree with the expansion rate scaling reported most recently. ${ }^{32}$ We intend to resolve this difference in subsequent scaling studies.

In summary, the plasma expansion rate is in very good agreement with theoretical predictions $^{29}$ at pressures above $\sim 3 \times 10^{-7}$ Torr in the EDG device. The magnetic field scaling of the expansion rate at higher pressures and low rigidity is measured to be proportional to $\mathrm{B}^{-2.2}$, in reasonable agreement with the theoretical scaling $\left(B^{-2}\right)$ in Eq. (3).

\section{ACKNOWLEDGMENTS}

This research was supported by the Office of Naval Research. 


\section{REFERENCES}

${ }^{1}$ E. H. Chao, R. C. Davidson, S. F. Paul, and K. A. Morrison, Phys. Plasmas 7, 831 (2000).

${ }^{2}$ E. H. Chao, S. F. Paul and R. C. Davidson, J. Vac. Sci. Technol. 17, 2034 (1999).

${ }^{3}$ E. H. Chao, R. C. Davidson and S. F. Paul, J. Vac. Sci. Technol. A 17, 2050 (1999).

${ }^{4}$ E. H. Chao, R. C. Davidson, S. F. Paul, and K. A. Morrison, Proceedings of the 1999 Workshop on Nonneutral Plasmas (Princeton University, 1999); American Institute of Physics Conference Proceedings, No. 498, edited by J. Bollinger, R. C. Davidson, and R. Spencer (American Institute of Physics, Melville, NY, 1999), p. 278.

${ }^{5}$ J. S. deGrassie and J. H. Malmberg, Phys. Rev. Lett. 39, 1077 (1977).

6 T. M. O’Neil, Phys. Scripta 59, 341 (1995).

${ }^{7}$ R. W. Gould, Phys. Plasmas 2, 2151 (1995).

${ }^{8}$ J. J. Bollinger, J. D. Presage, W. M. Itano, and D. J. Wineland, Phys. Rev. Lett. 54, $1000(1985)$.

${ }^{9}$ J. J. Bollinger, D. J. Wineland and D. H. E. Dubin, Phys. Plasmas 1, 1403 (1994).

${ }^{10}$ J. J. Bollinger, T. B. Mitchell, X.-P. Huang, W. M. Itano, J. N. Tan, B. M. Jelenkovic and D. J. Wineland, Phys. Plasmas 7, 7 (2000).

${ }^{11}$ C. F. Driscoll and K. S. Fine, Phys. Fluids B2, 1359 (1990).

${ }^{12}$ C. F. Driscoll, in Research Trends in Physics: Nonlinear and Relativistic Effects in Plasmas, edited by V. Stefan (AIP, New York, 1992), p. 454.

${ }^{13}$ X.-P. Huang and C. F. Driscoll, Phys. Rev. Lett. 72, 2187 (1994).

${ }^{14}$ D. Z. Jin and D. H. E. Dubin, Phys. Rev. Lett. 84, 1443 (2000).

${ }^{15}$ D. Durkin and J. Fajans, Phys. Fluids 12, 289 (2000). 
${ }^{16}$ D. Durkin and J. Fajans, Phys. Rev. Lett. 85, 4052 (2000).

${ }^{17}$ M. Kono, H. L. Pecseli and J. Trulsen, Physica Scripta 61, 489 (2000).

${ }^{18}$ D. A. Schecter, D. H. E. Dubin, K. S. Fine and C. F. Driscoll, Phys. Fluids. 11, 905 (1999).

${ }^{19}$ F. Anderegg, X. P. Huang, C. F. Driscoll, E. M. Hollmann, T. M. O’Neil, and D. H. E. Dubin, Phys. Rev. Lett. 78, 2128 (1997).

${ }^{20}$ F. Anderegg, X.-P. Huang, E. M. Hollmann, C. F. Driscoll, T. M. O’Neil, and D. H. E. Dubin, Phys. Plasmas. 4, 1552 (1997).

${ }^{21}$ D. L. Eggleston, Phys. Plasmas 4, 1196 (1997).

${ }^{22}$ D. H. E. Dubin, Phys. Plasmas. 5, 1688 (1998).

${ }^{23}$ D. H. E. Dubin, Phys. Rev. Lett. 79, 2678 (1997).

24 T. M. O’Neil and D. H. E. Dubin, Phys. Plasmas 5, 2163 (1998).

${ }^{25}$ D. H. E. Dubin and T. M. O’Neil, Rev. Mod. Phys. 71, 20 (1999).

${ }^{26}$ R. G. Greaves, M. D. Tinkle, and C. M. Surko, Phys. Plasmas 1, 1439 (1994).

${ }^{27}$ R. G. Greaves, and C. M. Surko, Phys. Plasmas 4, 1528 (1997).

${ }^{28}$ R. G. Greaves, and C. M. Surko, Phys. Rev. Lett. 85, 1883 (2000).

${ }^{29}$ R. C. Davidson and D. A. Moore, Phys. Plasmas 3, 218 (1996).

30 J. H. Malmberg and C. F. Driscoll, Phys. Rev. Lett. 44, 654 (1980).

${ }^{31}$ J. S. deGrassie and J. H. Malmberg, Phys. Fluids 23, 63 (1980).

${ }^{32}$ J. M. Kriesel and C. F. Driscoll, Phys. Rev. Lett. 85, 2510 (2000).

33 J. Notte and J. Fajans, Phys. Plasmas 1, 1123 (1994). 
${ }^{34}$ E. H. Chao, Ph.D. Thesis, Princeton University (1999).

${ }^{35}$ C. F. Driscoll and J. H. Malmberg, Phys. Rev. Lett. 50, 167 (1983).

${ }^{36}$ C. F. Driscoll, K. S. Fine and J. H. Malmberg, Phys. Fluids 29, 2015 (1986).

37 J. M. Kriesel, Ph.D. Thesis, University of California, San Diego, (1999). 
Fig. 1. The measured plasma expansion rates $\left(d\left\langle r^{2}\right\rangle / d t\right)$ at a magnetic field of $B=610$ Gauss are plotted versus background neutral helium pressure. The squares denote the previous data, ${ }^{1}$ the diamonds denote the new data, and the solid curve is a combination of the theoretical prediction in Eq. (3) plus a constant offset. The plasma line density is $N_{L}=3.41 \times 10^{7}$ electrons $/ \mathrm{cm}$.

Fig. 2. The measured plasma expansion rates $\left(d\left\langle r^{2}\right\rangle / d t\right)$ at a magnetic field of $B=300$ Gauss are plotted versus background neutral helium pressure. Theoretical curves for plasma temperatures of $T=1,1.5,2$, and $4 \mathrm{eV}$ are included for comparison. The plasma line density is $N_{L}=2.85 \times 10^{7}$ electrons $/ \mathrm{cm}$.

Fig. 3. The measured plasma expansion rates $\left(d\left\langle r^{2}\right\rangle / d t\right)$ are plotted versus magnetic field strength $B$. The points are best fit by a curve proportional to $B^{-2.19}$. Curves for the lower-pressure scaling ${ }^{1}$ of $B^{-1.5}$ and the theoretical scaling $B^{-2}$ are also included. 


\section{FIGURES}

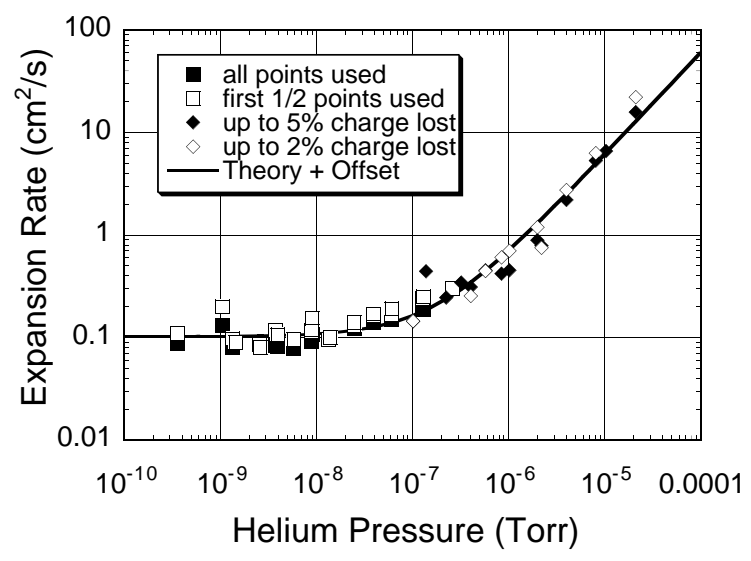

FIG. 1. 


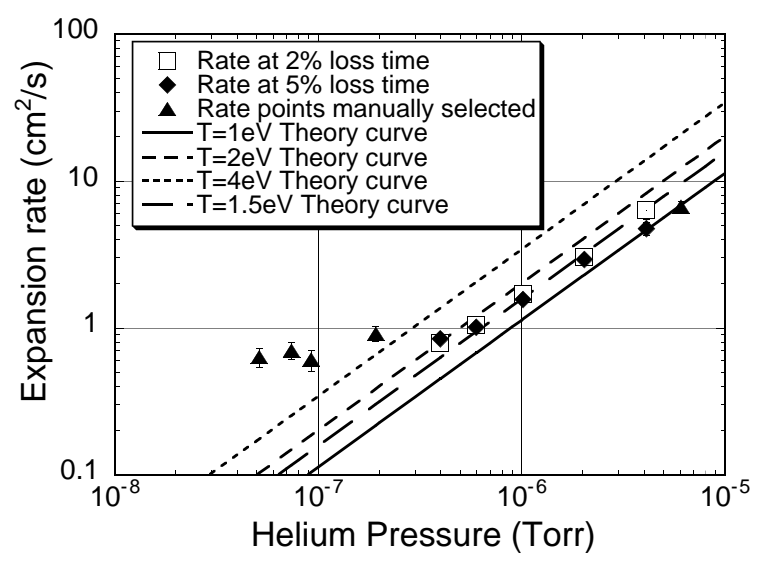

FIG. 2. 


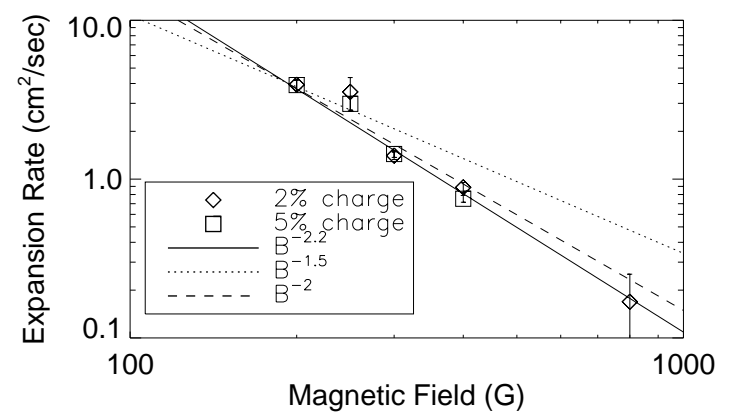

FIG. 3. 


\section{External Distribution}

Plasma Research Laboratory, Australian National University, Australia

Professor I.R. J ones, Flinders University, Australia

Professor J oão Canalle, Instituto de Fisica DEQ/IF - UERJ , Brazil

Mr. Gerson O. Ludwig, Instituto Nacional de Pesquisas, Brazil

Dr. P.H. Sakanaka, Instituto Fisica, Brazil

The Librarian, Culham Laboratory, England

Library, R61, Rutherford Appleton Laboratory, England

Mrs. S.A. Hutchinson, JET Library, England

Professor M.N. Bussac, Ecole Polytechnique, France

Librarian, Max-Planck-Institut für Plasmaphysik, Germany

J olan Moldvai, Reports Library, MTA KFKI-ATKI, Hungary

Dr. P. Kaw, Institute for Plasma Research, India

Ms. P.J . Pathak, Librarian, Insitute for Plasma Research, India

Ms. Clelia De Palo, Associazione EURATOM-ENEA, I taly

Dr. G. Grosso, Instituto di Fisica del Plasma, Italy

Librarian, Naka Fusion Research Establishment, J AERI, J apan

Library, Plasma Physics Laboratory, Kyoto University, J apan

Research Information Center, National Institute for Fusion Science, J apan

Dr. O. Mitarai, Kyushu Tokai University, J apan

Library, Academia Sinica, Institute of Plasma Physics, People's Republic of China

Shih-Tung Tsai, Institute of Physics, Chinese Academy of Sciences, People's Republic of China

Dr. S. Mirnov, TRINITI, Troitsk, Russian Federation, Russia

Dr. V.S. Strelkov, Kurchatov Institute, Russian Federation, Russia

Professor Peter Lukac, Katedra Fyziky Plazmy MFF UK, Mlynska dolina F-2, Komenskeho Univerzita, SK-842 15 Bratislava, Slovakia

Dr. G.S. Lee, Korea Basic Science Institute, South Korea

Mr. Dennis Bruggink, Fusion Library, University of Wisconsin, USA

Institute for Plasma Research, University of Maryland, USA

Librarian, Fusion Energy Division, Oak Ridge National Laboratory, USA

Librarian, Institute of Fusion Studies, University of Texas, USA

Librarian, Magnetic Fusion Program, Lawrence Livermore National Laboratory, USA

Library, General Atomics, USA

Plasma Physics Group, Fusion Energy Research Program, University of California at San Diego, USA

Plasma Physics Library, Columbia University, USA

Alkesh Punjabi, Center for Fusion Research and Training, Hampton University, USA

Dr. W.M. Stacey, Fusion Research Center, Georgia Institute of Technology, USA

Dr. J ohn Willis, U.S. Department of Energy, Office of Fusion Energy Sciences, USA

Mr. Paul H. Wright, Indianapolis, Indiana, USA 
The Princeton Plasma Physics Laboratory is operated by Princeton University under contract with the U.S. Department of Energy.

\author{
Information Services \\ Princeton Plasma Physics Laboratory \\ P.O. Box 451 \\ Princeton, NJ 08543
}

Phone: 609-243-2750

Fax: 609-243-2751

e-mail: pppl_info@pppl.gov

Internet Address: http://www.pppl.gov 